\title{
ALTA HOSPITALAR E O CUIDADO DO RECÉM-NASCIDO PREMATURO NO DOMICÍLIO: VIVÊNCIA MATERNA
}

\author{
Hospital and care of the premature newborn at home: maternal experiences. \\ Alta hospitalaria y el cuidado de los recién-nacidos prematuros en el hogar: experiencias \\ de la madre.
}

Mirna Albuquerque Frota ${ }^{1}$
Elis Mayre da Costa Silveira Martins ${ }^{4}$

\section{RESUMO}

Objetivou-se conhecer a percepção da mãe sobre a alta hospitalar e o cuidado do recém-nascido prematuro no domicílio após a primeira semana de alta. Pesquisa descritiva, de abordagem qualitativa, com uso da entrevista semiestruturada para coleta de dados, desenvolvida no ambulatório de seguimento do prematuro (follow-up) do Hospital da Rede Pública Estadual de Fortaleza, em outubro e novembro de 2011. As participantes foram nove mães de recém-nascido prematuro após primeira semana de alta. Aplicou-se análise do conteúdo. Os resultados apontaram para as categorias: Orientações sobre o cuidado com o prematuro durante a alta hospitalar; Sentimentos e dificuldades com a chegada do bebê no domicílio; e Apoio familiar no cuidado do prematuro. 0 estudo evidenciou que algumas mães não receberam orientações da equipe multiprofissional da neonatologia acerca do cuidado bebê após alta hospitalar, reforçando que elas levam o bebê para o domicílio sem estar preparadas para a nova realidade.

Palavras-chave: Enfermagem neonatal. Cuidado do lactente. Alta do paciente. Relações profissional-família.

\begin{abstract}
It aimed at learning about the mother's perception in a hospital and the care of premature newborns at home after the first week of discharge. Descriptive, qualitative approach, using semistructured interviews to collect data, developed in the outpatient follow-up of premature (Follow up) of the State Public Hospital Network of Fortaleza, in October and November 2011. The participants were nine mothers of preterm infants after the first week of discharge. It was applied the analyzis the content for data analysis. The results pointed to the categories: Guidelines on the care of premature infants during discharge; feelings and difficulties with the baby's arrival at home; family support in the care of premature infants. The study showed that some mothers were not instructed interdisciplinary team of neonatology care about the baby after discharge, stressing that they take the baby to the household without being prepared for the new reality.
\end{abstract}

Keywords: Neonatal Nursing. Infant Care. Patient Discharge. Professional-Family Relations.

\section{Resumen}

Dirigido a aprender acerca de la percepción de la madre sobre el alta hospitalaria y el cuidado de los recién-nacidos prematuros en el hogar después de la primera semana de alta. Enfoque descriptivo, cualitativo, con entrevistas semiestructuradas para recopilar datos, desarrollado en el ambulatorio de seguimiento del prematuro (Follow Up) del Hospital de la Red Pública del Estado de Fortaleza, en octubre y noviembre de 2011. Participaron nueve madres de bebés prematuros después de la primera semana de alta. Se aplicó el análisis de contenido para la observación de los datos. Los resultados apuntan para las siguientes categorías: Orientaciones para el cuidado con los bebés prematuros durante el alta; Sentimientos y dificultades con la llegada del bebé al hogar; Apoyo familiar en el cuidado de los bebés prematuros. El estudio demostró que algunas madres no recibieron instrucciones del equipo interdisciplinario de atención de neonatología acerca del cuidado con el bebé después del alta, reforzando que las madres llevan al bebé a la casa sin estar preparadas para la nueva realidad.

Palabras clave: Enfermería Neonatal. Cuidado del Lactante. Alta del Paciente. Relaciones Profesional-Familia.

\footnotetext{
'Enfermeira. Doutora em Enfermagem pela Universidade Federal do Ceará - UFC. Docente do Mestrado em Saúde Coletiva e da Graduação em Enfermagem da Universidade de Fortaleza - UNIFOR. Líder do Núcleo de Pesquisa e Estudo em Saúde da Criança - NUPESC/CNPq/UNIFOR. Fortaleza-CE. Brasil. Email:mirnafrota@unifor.br; ²Enfermeira. Membro do Núcleo de Pesquisa e Estudo em Saúde da Criança - NUPESC/CNPq/UNIFOR. Fortaleza-CE. Brasil. E-mail: priscillafuratdo@hotmail.com; ${ }^{3}$ Enfermeira. Membro do Núcleo de Pesquisa e Estudo em Saúde da Criança - NUPESC/CNPq/UNIFOR. Fortaleza-CE. Brasil. Email: stephaniribeirom@hotmail.com; ${ }^{4}$ Enfermeira. Mestranda em Saúde Coletiva pela Universidade de Fortaleza - UNIFOR. Bolsista da Fundação Cearense de Amparo à Pesquisa - FUNCAP. Membro do Núcleo de Pesquisa e Estudo em Saúde da Criança - NUPESC/CNPq/UNIFOR. Fortaleza-CE. Brasil. E-mail: eliscsilveira@yahoo.com.br; ${ }^{5}$ Enfermeira. Doutora em Farmacologia da Universidade Federal de Fortaleza-UFC. Docente da Graduação em Enfermagem da Faculdade Metropolitana da Grande

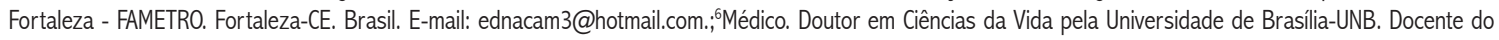
Mestrado em Saúde Coletiva e da Graduação em Nutrição da UNIFOR. Fortaleza - CE. Brasil. Email: carlosbruno@unifor.br.
} 


\section{INTRODUÇÃO}

A prevalência de recém-nascidos prematuros (RNPT) é de aproximadamente $6,7 \%$ no Brasil. Os RNPT apresentam risco cinco vezes maior de morrer durante o primeiro ano de vida do que crianças nascidas a termo, mesmo com ajustes para morbidade materna efatores sociodemográficos. Logo, a prematuridade exerce relevante papel nos óbitos infantis, e são necessárias intervenções efetivas para a redução desta mortalidade..$^{1-3}$

A internação na Unidade de Terapia Intensiva Neonatal (UTIN), tecnologicamente equipada, e a assistência especializada do profissional de saúde são consideradas medidas potenciais na redução da mortalidade infantil, especialmente no componente neonatal. No entanto, o seguimento da criança prematura após alta hospitalar ainda é fator preocupante. Diante desse contexto, surge a premência de humanizar a assistência ao prematuro e seus familiares, visando valorizar a recuperação da saúde da criança, a formação e manutenção do vínculo por meio da linguagem afetiva entre mãe e filho, cuidados diários, participação em grupo das mães que passam pela mesma realidade e orientações durante a internação. ${ }^{4,5}$

Indubitavelmente, o diálogo e a interação do profissional enfermeiro com a família do RNPT possibilita conhecer o contexto social, cultural e econômico, além de capacitar e estimular os familiares para a realização dos cuidados adequados à criança após a alta hospitalar. ${ }^{6}$

0 modelo assistencial tradicional na UTIN passou e passa por modificações em relação ao cuidado centrado no RNPT, destinando espaço para os pais e incorporando novas medidas para humanizar o serviço. Para efetivar essa prática, a UTIN tem permitido livre acesso dos pais para visitar os filhos, além da permanência por tempo ilimitado junto ao bebê internado. No entanto, vários fatores contribuem para que, na prática, a dinâmica do serviço seja diferente, justificada pela realização de procedimentos invasivos, horário da visita médica, espaço físico pequeno e escassez de recursos humanos. Em relação aos outros membros da família, a situação é ainda comprometedora, poucos serviços permitem a entrada de familiar que não os pais. ${ }^{7-8}$

Apesar dos direitos adquiridos pelos pais após 0 surgimento da legislação dos direitos da criança, liberação de visitas e estudos evidenciando as vantagens do envolvimento materno no cuidado hospitalar, observa-se que pouco se tem evoluído no contexto do empoderamento materno e envolvimento mãe/bebê/profissional, o qual serviria de recurso para o cuidado do prematuro em domićlío. .-9,6 $^{-9}$

A alta hospitalar planejada, seguida de plano de cuidados, faz parte de um processo complexo que deve envolver, entre outras, a equipe de enfermagem, que se caracteriza como assistência vigilante, humanizada e individualizada. No entanto, observa-se que alguns profissionais ainda não visualizam a atividade como algo essencial na promoção da saúde do prematuro. ${ }^{10}$
Os profissionais tendem a priorizar aspectos imediatos da assistência, excetuando a atividade educativa e o preparo para alta, bem como a previsão de problemas que ocorrerão no domićlio e como solucioná-los, tornando a transição do hospital para o domicílio algo desafiador para a equipe de enfermagem. ${ }^{11-}$ 13

Sob essa perspectiva, a promoção da saúde deverá ser envolvida no plano de cuidados da equipe de enfermagem a nível terciário, envolvendo os pais na responsabilidade do cuidado, considerando que os riscos e agravos no período pósneonatal não se dissipem à medida que o neonato seja assistido com segurança pela família.

Diante dessa problemática, surge a necessidade de aprofundamento sobre a temática, visto que os cuidados maternos após alta é determinante no processo de manutenção da saúde do bebê. A partir destas reflexões, a presente pesquisa objetivou conhecer a percepção da mãe sobre a alta hospitalar e sobre o cuidado do recém-nascido prematuro no domicílio após a primeira semana de alta.

\section{METODOLOGIA}

Trata-se de uma pesquisa exploratória-descritiva com abordagem qualitativa. A pesquisa qualitativa visa descrever $\mathrm{e}$ explorar aspectos de uma situação, assim como trabalhar com o universo de significados, motivos, aspirações, crenças e atitudes. ${ }^{14}$

Foi desenvolvida no ambulatório de seguimento do prematuro (follow-up) de um Hospital da Rede Pública Estadual de caráter terciário, pertencente à Secretaria Executiva da Regional VI no município de Fortaleza no Estado do Ceará, Brasil. A referida unidade conta com a participação de equipe multiprofissional, sendo 02 enfermeiros, 01 neuropediatra, 01 terapeuta ocupacional, 01 fonoaudióloga, 02 pediatras, 01 neonatologista e 01 médico ultrassonografista.

Participaram nove mães de RNPT que receberam alta da UTIN e compareceram ao follow-up na primeira semana após alta. Os seguintes critérios de inclusão foram adotados: mães de RNPT que estivessem na primeira consulta no follow-up após alta da UTIN, primíparas e alfabetizadas. Os critérios de exclusão: mãe com doença mental; mãe de RNPT que precisava de oxigenoterapia no domicílio; mãe de RNPT com malformação; mãe de RNPT traqueostomizado.

Para determinar o número de participantes na pesquisa foi utilizada uma ferramenta conceitual denominada saturação teórica, a qual interrompe a captação de novos sujeitos, fundamentada na redundância e convergência de sentido e significado obtido durante a coleta e análise dos dados. ${ }^{15}$

Os dados foram coletados mediante a técnica de observação não participante por meio de visitas semanais à instituição e diário de campo durante os meses de agosto e setembro, e entrevistas do tipo semiestruturadas aplicadas em outubro e novembro de 2011. Estas se iniciaram com as 
Alta hospitalar e cuidado do prematuro no domicílio

seguintes perguntas orientadoras: Como aconteceu o momento da alta hospitalar em relação às orientações recebidas? Como aconteceu a interação da família na primeira semana de alta? Durante seu transcorrer, foram formuladas outras questões com o intuito de explorar as verbalizações e aprofundar a compreensão dos conceitos emergidos.

As entrevistas, com o consentimento dos sujeitos, foram gravadas, tiveram duração de 10 minutos em média; logo após foram ouvidas e transcritas na íntegra. Para garantia do anonimato, os sujeitos foram identificados pela letra "M" de mãe, seguida de numeração que corresponde à ordem cronológica de realização das entrevistas. As leituras sucessivas do material serviram para análise e elaboração das categorias do estudo. A técnica de análise das informações foi análise de conteúdo ${ }^{16}$ com as etapas: pré-análise ou organização do material; a exploração desse material por meio da classificação, codificação e categorização; e a interpretação dos resultados. Após leitura cuidadosa, os dados foram organizados, interpretados, analisados e, por fim, reduzidos a categorias.

Os aspectos éticos estiveram presentes no decorrer da pesquisa, baseados na Resolução n¹96/96 do Conselho Nacional de Saúde ${ }^{17}$. A pesquisa foi submetida ao Comitê do Hospital Geral de Fortaleza (HGF), aprovada sob o Parecer de №. 201001/11, e os sujeitos participantes assinaram o Termo de Consentimento Livre e Esclarecido.

\section{RESULTADOS E DISCUSSÃO}

A análise do material empírico possibilitou a aproximação com o objeto de estudo, identificando como as mães visualizam a alta hospitalar do filho, os sentimentos e apoio social que surgem ao conviver com o RNPT após a primeira semana de alta hospitalar. Desse modo, para melhor compreensão dessa relação, os dados foram apresentados a partir de três categorias temáticas: orientações sobre o cuidado com o prematuro na alta hospitalar; sentimentos e dificuldade com a chegada do bebê no domicílio; e apoio familiar no cuidado do prematuro.

\section{Orientações sobre o cuidado com o prematuro na alta hospitalar}

Buscou-se conhecer por meio das falas das mães que orientações foram recebidas durante o preparo para alta hospitalar e em que momento da internação iniciou-se esse processo. Esta categoria, que se constitui na condição causal da experiência vivenciada, revela a forma que as orientações foram passadas.

[...] conversaram comigo para cuidar bem do bebê! Falaram sobre a amamentação e banho de sol. Recebiessas orientações no momento da alta (M3).
[...] para ter cuidado, lavar as mãos antes de pegar no bebê, ter muito cuidado para ele não ficar doente e não entrarágua no ouvido durante o banho. Aprendi esses cuidados durante as visitas (M5).

Recebi orientações que o bebê não deveria receber visitas por 3 meses, que teria que ficar acordando de $3 \mathrm{em} 3$ horas, porque não pode perder peso de jeito nenhum, ele não poderia tomar vacinas até chegar a um determinado peso; lógico, as pessoas que fossem pegar nele teriam que estar sempre com as mãos limpas. (M7).

[...] eles me disseram que tivesse cuidado, lavasse as mãos antes de pegar no bebê, não posso ficar fora de casa com ela, tenho que banhá-la duas vezes ao dia, dar banho de sol e a vitamina. Na hora da alta repetiram isso várias vezes (M9).

Percebe-se nos depoimentos que as mães receberam informaç̃oes sobre o cuidado do bebê. No entanto, poucos cuidados foram revelados pelas depoentes; com isso, surgem questionamentos sobre as orientações não acontecerem de forma sistemática e planejada ou a possibilidade de fatores como ansiedade e estresse gerado na UTIN interferirem na aprendizagem das mães.

Ressalta-se que a capacitação das mães para alta hospitalar inicia-se após a estabilidade clínica do RNPT e a disponibilidade materna de aprender. As informações não podem ser apenas assimiladas pelos pais, mas sobretudo compreendidas e incorporadas no cuidado domiciliar do recémnascido após alta. 0 desenvolvimento de habilidades e aquisição de conhecimento devem partir dos cuidadores por meio de estratégias estimuladoras desenvolvidas pela equipe de enfermagem. ${ }^{9}$

Além dos cuidados citados pelas pesquisadas, existem outros cuidados relacionados à prematuridade que poderiam ser informados pelos profissionais da saúde, tais como: cuidados ao receber visita, estimular o bebê a sugar, manutenção da temperatura do bebê, evitar lugares úmidos e com aglomerados de pessoas, limpeza da casa com pano úmido, uso de medicações de acordo com a prescrição médica, impor tância do retorno das consultas, sinais de perigo para a saúde do bebê, pausar amamentação caso o bebê fique dispneico, entre outros. $^{18}$

Compreende-se que, além da instabilidade do bebê e do ambiente da UTIN, a existência das rotinas institucionais dificulta o aprendizado das mães; todavia, o conhecimento pode ser realizado de modo gradual, com estratégias de empoderamento. As orientações implementadas pela equipe de enfermagem no preparo da alta hospitalar da criança devem ser concisas, de 
fácil compreensão e que atendam às necessidades individualizadas. ${ }^{18}$

A implementação de rotina no acolhimento dos pais de bebês prematuros da UTI neonatal, com atendimento humanizado e terapêutica holística, permite a valorização do envolvimento da mãe no processo de recuperação do filho, dando-lhes a oportunidade de participação, compreensão e esclarecimento da recuperação e reabilitação da saúde do neonato. Desta forma, busca-se a valorização do bem-estar biopsicossocial e estabilidade emocional como capacidade da família em cuidar.

0 diálogo com os pais na UTIN representa um elemento ímpar na construção da sua relação com a equipe de saúde durante o processo de internação do recém-nascido, permitindo escuta sensível para as reais premências, podendo reduzir o seu estresse e sensibilizá-los sobre a qualidade de vida do filho. ${ }^{11-12}$

Perceber a educação em saúde como capaz de provocar mudanças, estabelecer ligação entre a qualidade de vida e compromisso com a vida provocam mudança no tratamento da doença, de forma que a saúde não seja vista apenas como responsabilidade do profissional de saúde e dever do Estado. ${ }^{19}$

Logo, compartilhar conhecimentos com a família do prematuro faz parte da assistência de enfermagem para o alcance da integralidade do cuidado, que deve ser inserida por meio de metodologias ativas. Isso remete à necessidade de discutir a organização do trabalho da equipe, pois novas estratégias e metodologias podem perder potencial inovador quando se tornam apenas mais uma tarefa a ser cumprida ou uma ação estanque, divorciada de seu sentido ou finalidade. ${ }^{10}$ Assim, evidenciou-se a deficiência na assistência com a falta de estratégias para essa parcela da população em processo de alta hospitalar.

[...] as orientações foram oferecidas ao lado da incubadora, e às vezes não entendia muito bem. Não recebi cartilha, apenas papéis com a data das consultas e exames. [...] falavam muito rápido, os médicos e as enfermeiras eram apressados e sem tempo (M1).

Outro ponto sensível nesse agir que se soma à ausência de estratégias é o tempo limitado dos profissionais, que pode ser justificado pela falta de recursos humanos ou acúmulo de atividades. Por fim, a organização do trabalho, o plano de cuidados para alta hospitalar e a inserção de metodologias ativas com os pais são considerados ferramentas na articulação do processo de alta hospitalar do neonato e, consequentemente, para a continuidade do cuidado que visa espaço para além dos muros dos serviços de saúde, incidindo sobre a ampliação de escolhas saudáveis para os prematuros. ${ }^{18} \mathrm{Na}$ percepção de parte das entrevistadas, a falta de orientações sobre o cuidado com o bebê no domicílio foi uma constante.
[...] quando ele teve alta eles não informaram nada [...] me sentia uma estranha com aquele bebê tão pequeno(M2).

Todos os dias ia visitá-lo na UTI e cuidava dele dando o leite e trocando fraldas, mas alguns profissionais não queriam deixar fazer. Quando ele recebeu alta da UTI não falaram nada, recebi apenas vários papeis com datas (M4).

Quando recebi alta da UTI não informaram nada sobre os cuidados que deveria ter com ele, e não sabia como cuidar. (M8).

Não há justificativa para que as mães recebam alta hospitalar sem as orientações necessárias para o cuidado seguro do bebê. A equipe de saúde precisa ser conscientizada sobre a importância das orientações, visando promover saúde em seres frágeis como o prematuro após a saída do hospital, pois cuidados básicos podem impedir várias doenças respiratórias e infecciosas que levam ao alto índice de mortalidade no primeiro ano de vida. Orientar os pais sobre a forma de cuidar do bebê prematuro requer uma linguagem bem estruturada e documentada.

Neste sentido, estudos realizados mostram que 0 despreparo das mães interfere de forma negativa na saúde do bebê, e que o sentimento de exclusão na função materna provocados durante a internação pode repercutir no cuidado domiciliar do bebê. Outra pesquisa evidenciou que as informações recebidas pelas mães de RNPT não acontecem de forma padronizada e que ainda há dúvidas a respeito do banho, pega do bebê e os riscos do RN prematuro no domicílio, além do medo de que o filho retorne para o hospital. ${ }^{6,9,18}$

As pesquisadoras constataram ainda que as orientações de alta hospitalar deveriam vir acompanhadas por palestras, cartilhas ou manuais que as ajudassem no cuidado diário. Logo, existe a necessidade de desenvolver habilidades e transmitir conhecimentos específicos à família para o cuidado hospitalar e domiciliar do bebê pré-termo durante a internação. ${ }^{9,18}$

\section{Sentimentos e dificuldades com a chegada do bebê no domicílio}

A realidade temática sobre o cuidado da criança prematura no domićlio é revelada por percepções diferentes. As expectativas e idealizações criadas pela gestante e família durante a espera da criança transformam-se em angústia e incerteza após o nascimento de uma criança prematura, por se tratar de um recém-nascido de risco, que apresenta imaturidade anatômica e fisiológica e necessita de cuidados especiais. ${ }^{4,7}$

A chegada ao domicílio com o bebê representa 0 rompimento com o mundo da internação e gera situaç̃̃es próprias do contexto domiciliar. É o momento aguardado pelos pais. No entanto, surge uma oposição de sentimentos 
permeados por tranquilidade, alegria e medo. As mães associam o prematuro a uma criança frágil, susceptível a intercorrências devido ao tamanho.

Senti muito medo quando fui para casa com ele porque era meu primeiro filho e pequenininho... Tinha medo de não saber cuidar, pra mim ele ia adoecer ou parar de respirar e eu não ia saber o que fazer (M4).

Tive medo de dar banho porque ele era muito molezinho e pequeno [...] tinha medo de colocar ele para dormir, não sabia a posição certa (M5).

[...] mas não esperava que fosse ser tão difícil. Você não sabe como é delicado, ele é muito pequeno... para mim ele é uma criança especial, delicada e que tenho que ter mais cuidado (M2).

As mães que se referiram a medo e insegurança com a chegada do recém-nascido em domicilio receberam informações dos profissionais da UTIN sobre os cuidados necessários com o prematuro. Contudo, esses sentimentos podem estar associados ao fato de os filhos terem permanecido por longo período ( 15 dias a 4 meses) na UTIN. 0 longo período de internação do bebê e a privação de carinho e afeto aumentam o estresse da mãe e família, o que pode prejudicar a continuidade do vínculo e apego. ${ }^{6}$

A chegada ao domicilio é um período crítico de adaptação do neonato e dos pais ao novo ambiente, pois a partir desse momento serão os responsáveis por todo o cuidado prestado ao novo membro da família. ${ }^{11}$ As lembranças da instabilidade de saúde do filho durante a internação na UTIN marcam as mães, levando-as a acreditar que algo de ruim pode acontecer com o bebê, o que limita cuidados e traz insegurança no dia a dia. ${ }^{18}$ Durante a apropriação do cuidar do RNPT no domicílio, revelamse sentimentos de apreensão com as possíveis complicações, porque 0 associam a um ser frágil e com maior probabilidade de doenças graves do que a criança a termo.

A alta planejada em conjunto com a família e as visitas domiciliares constituem fonte de apoio na redução de ansiedade e medo. 0 fornecimento de informações, atenção humanizada e seguimento desse processo com implementação de intervenções que aumentem a capacidade de adaptação da família reduzem os riscos de estresse e o número das reinternações frequentes. ${ }^{9}$

Bebês prematuros, ao receberem alta da UTIN para o domicilio, requerem da família atenção e cuidados especiais, por terem maior risco de complicações. Porém, frequentemente as mães se tornam responsáveis por esses cuidados sem portarem total segurança e capacitação para assumirem a tarefa. ${ }^{10}$ Apesar do medo e da dificuldade encontrada, as pesquisadas relataram que levar o bebê para o domicílio gerou momentos de alegria e sensações de vitória.
Eu tava louca para chegar em casa não aguentava mais ficar no hospital com ele. Aqui é muito bom, a casa da gente é muito melhor (M3).

Eu fiquei muito feliz, uma vitória conquistada. Passei dias difíceis no hospital, mas sei que agora as coisas vão melhorar (M2).

Foi um momento feliz, um momento muito esperado. Eu estava cheia de expectativas [...] você não vê a hora de levar seu filho para casa (M7).

Reconhecendo as limitações desse estudo, que impossibilita generalizações, observa-se que algumas mães vivenciam a alta hospitalar como vitória e recompensa pelos momentos difíceis gerados com a internação. 0 ato de cuidar do bebê no domicílio e tê-lo perto gera satisfação inexplicável. Isso faz com que o trabalho de cuidar do filho prematuro seja mais aprazível. Presenciar a vinda do bebê ao domicílio leva a família a arquitetar um futuro, congeminando esperanças em relação ao estudo, trabalho e vida social estável, mudando, assim, seu modo de viver.

Contudo, o estudo aponta um número significativo de evasão do seguimento ambulatorial e um grande número de reinternações hospitalares de RNPT egressos da UTIN. Esta realidade mostra que a família deve ser apoiada não apenas na hospitalização, mas após alta do filho. ${ }^{20}$

\section{Apoio familiar no cuidado do prematuro}

Além da instabilidade do bebê e do ambiente da UTIN, a existência das rotinas institucionais, como os horários rígidos e a restrição da visita aos familiares do recém-nascido, resultam em afastamento dos familiares. No entanto, observase que a chegada do bebê no domićilio atrai amigos e familiares. A ajuda com o cuidado do prematuro parte, sobretudo, de pessoas próximas à mãe, que além de auxiliar nos cuidados diários com o recém-nascido, contribuem para a manutenção do equilíbrio emocional da puérpera, que se apresenta fragilizada devido ao período em que o filho esteve internado na UTIN. O apoio do familiar no cuidar foi descrito como referência de segurança em atender as necessidades do bebê.

Meu marido e minha sogra me ajudam muito com ele. Às vezes eu estou cansada e eles me ajudam muito (M3).

[...] me sinto insegura. Eu começo a dar banho nele e minha vizinha lava a cabeça dele (M5)

0 apoio da minha familia foi realmente o mais importante, porque eles estavam do meu lado me ajudando, consolando, apoiando [...] (M7). 
Em nenhum momento estive sozinha. Todos da minha familia me ajudam. E também sentem que ela é especial e cuidam dela com mais amor. E isso me ajuda muito (M2).

Meu marido me ajuda, quando a gente vai dormiré ele que acorda para cuidar dela (M9).

Ainda corroborando os achados nessa pesquisa, é possível verificar que o apoio da família tem papel significativo na adaptação da mãe à nova dinâmica familiar e na aquisição da autoconfiança no cuidar. A experiência transmitida das gerações anteriores representa forte apoio e diminui sentimentos de insegurança frequentes nessa situação. ${ }^{9}$

Por estar no puerpério, período de forte instabilidade emocional, e fragilizada pelo período em que esteve afastada do filho, a mulher requer maior atenção de familiares e do marido, para que atravesse momento complicado e vença a insegurança de cuidar do bebê sem o auxílio de profissionais.

A mãe sente-se mais confortável e segura para realizar cuidados diários por receber apoio de pessoas experientes, como a avó, mãe e tia, que colaboraram marcantemente no cuidado do bebê, com ações auxiliares. ${ }^{10} \mathrm{As}$ mudanças ocorridas devido o nascimento de uma criança prematura podem ter interferência significativa na dinâmica familiar; logo, o apoio social representa uma contribuição expressiva para os pais do recém-nascido.

\section{CONSIDERAÇÕES FINAIS}

Este estudo permitiu conhecer as experiências vivenciadas pela mãe durante a alta hospitalar e o cuidado do RNPT no domicílio após a primeira semana de alta. As observações realizadas mostraram que algumas mães levam 0 bebê para o domicílio sem estar preparadas para esta realidade. Estes aspectos intensificam a importância de fornecer aos cuidadores de prematuros, durante a internação do bebê, as informações de forma a envolver a mãe no processo de aprendizagem, não apenas como receptora passiva de informações, mas, destacadamente, como sujeito ativo da educação.

Assim, a equipe de enfermagem, responsável pelo ato de cuidar, deve permitir que as necessidades sentidas pelas mães aflorem, em vez de determiná-las. Devem desenvolver ações de assistência ao bebê junto às mães, estímulo ao toque e apropriação, mesmo percebendo que os sentimentos oscilam durante o processo de internação, pois as mães provavelmente nunca se sentirão prontas para cuidar do bebê prematuro, em virtude dos sentimentos de apreensão, inquietação e medo, comuns após alta hospitalar.

0 estudo evidenciou que algumas mães não receberam orientações da equipe multiprofissional da UTIN acerca do cuidado que deve ser oferecido ao bebê no domićlio, reforçando a necessidade de maior aproximação e interação dos profissionais de saúde com os pais, para que essas informações sejam transmitidas e, com isso, a qualidade do cuidado prestado no hospital seja mantida.

A criação de programas educacionais em unidades neonatais pode vir a facilitar o aprendizado das mães sobre a assistência que deverá ser prestada ao prematuro no domicílio, for talecendo o vínculo afetivo e diminuindo o sentimento de insegurança, muitas vezes apresentado pelos pais nessa situação.

0 apoio social, principalmente quando oferecido pela família, mostrou-se forte aliado para adaptação dos pais à nova realidade. Em vários momentos foi citada pelas mães a ajuda de familiares no cuidado com o bebê e no supor te emocional para puérpera, revelando a expressiva contribuição que esse apoio representa para o restabelecimento da dinâmica familiar e para a construção da autoconfiança materna na assistência do seu filho, posto que, apesar do medo e insegurança muitas vezes presente, a mãe continua sendo a principal cuidadora.

Considerando os achados nesta pesquisa, destacamos a necessidade de capacitação adequada das mães no período de internação do filho prematuro, enfocando a dimensão social em que vivencia a construção de valores. Nas atividades desenvolvidas com as mães, deve-se atentar para a inserção de elementos éticos, biológicos, culturais e sociais nas discussões coletivas e no diálogo individualizado, reiterando que tais ações devem envolver a família, uma vez que essa instituição é a principal promotora da singularização do indivíduo na sociedade.

\section{REFERÊNCIAS}

1-Ministério da Saúde (Brasil). Secretaria de Vigilância em Saúde. Secretaria de atenção à Saúde. Atenção à Saúde do Recém-Nascido. Guia para os Profissionais de Saúde. Série A. Normas e Manuais Técnicos. Volume 1. Brasilia: DF; 2011.

2-Ministério da Saúde (Brasil). Departamento de informática do Sistema Único de Saúde. [citado em 2012 jan.02]. Disponivel em: <http:// www2.datasus.gov.br/DATASUS/index>.

3-Santos RV, Penna CMM. Educação em saúde como estratégia para o cuidado à gestante, puérpera e ao recém-nascido. Texto $\&$ contexto enferm. 2009 out/dez; 18(4): 652-60.

4-Vasconcelos MGL, Leite AM, Scochi CGS. Significados atribuídos à vivência materna como acompanhante do recém-nascido pré-termo e de baixo peso. Rev. bras. saúde matern. infant. 2006 jan/mar; 6(1): 47-57.

5-Fonseca LMM, Leite AM, Vasconcelos MGL, Castral TC, Scochi CG. Cartilha educativa on line sobre os cuidados com o bebê pré-termo: aceitação dos usuários. Ciênc. cuid. saúde. 2007 abr/jun; 6(2): 238-44. 
6-Viera CS, Mello DF. 0 seguimento da saúde da criança pré-termo e de baixo peso egressa da terapia intensiva neonatal. Texto \& contexto enferm. 2009 jan/mar; 18(1): 74-82.

7- Bernardino E, Segui MLH, Lemos MB, Peres AM. Enfermeira de ligação: uma estratégia de integração em rede. REBEN. 2010 maio/jun.; 63(3): 459-63.

8- Sousa JC, Silva LMS, Guimaraes TA. Preparo para a alta hospitalar de recém-nascido em unidade de tratamento intensivo neonatal: uma visão da família. Pediatria (São Paulo). 2008; 30(4): 217-27.

9- Couto FF, Praça NS. Preparo dos pais de recém-nascido prematuro para alta hospitalar: Uma revisão bibliográfica. Esc. Anna Nery Rev. Enferm. 2009 out/dez; 13(4): 886-91.

10- Silva MCM, Sousa RMC, Padilha KG. Destino do paciente após alta da unidade de terapia intensiva: unidade de internação ou intermediária? Rev. Latino-Am. Enfermagem. 2010 mar./abr.; 18(2): 224-32.

11- Foust JB. Discharge planning as part of daily nursing practice. Appl Nurs Res. 2007 may; 20(2): 72-7.

12-Suzuki VF, Carmona EV, Lima MHM. Planejamento da alta hospitalar do paciente diabético: construção de uma proposta. Rev. Esc. Enferm. USP. 2011 abr.; 45(2): 527-32.

13- Maynard GOCW. Kirsh SR. Perioperative care of the geriatric patient with diabetes or hyperglycemia. Clin Geriatr Med. 2008 nov.; 24(4): 64965.

14- Minayo MCS. 0 desafio do conhecimento: pesquisa qualitativa em Saúde. 12. ed. São Paulo: Huncitec; 2010.

15-Fontanella BJB, Ricas J, Turato ER. Amostragem por saturação em pesquisas qualitativas em saúde: contribuições teóricas. Cad. saúde pública. 2008 jan.; 24(1): 17-20.

16- Bardin L. Análise de conteúdo. Lisboa: Edições 70; 2008.

17- Resolução No 196 de 10 de outubro de 1996: aprova as diretrizes e normas regulamentadoras de pesquisa envolvendo seres humanos. Diário Oficial da República Federativa do Brasil, Brasilia (DF), 16 out 1996: Seção 1:21082-5.

18- Siqueira, MBC, Dias MAB. A percepção materna sobre vivência e aprendizado de cuidado de um bebê prematuro. Epidemiol. serv. saúde. 2011 mar.; 20(1): 27-36.

19- Ministério da Saúde (Brasil). Secretaria de Vigilância em Saúde. Secretaria de atenção à Saúde. Política Nacional de Promoção da Saúde. Brasília(DF): Editora MS; 2006.

20- Hayakawa LM, Kayna TS, Rosseto EG, Souza SNDH, Bengozi TL. Incidência de reinternação de prematuros com muito baixo peso nascidos em um hospital universitário. Esc. Anna Nery Rev. Enferm. 2010 abr./jun.; 14(2): 324-9. 